\title{
Inter-cell and intra-cell layout design in a cellular manufacturing system
}

\begin{abstract}
Facility layout design problems are a group of problems that involve the partitioning of a region into work centers or departments to minimize the costs associated with interactions between the work centers and departments. In cellular manufacturing systems, facility layout problem aims to find the most efficient arrangement of facilities within the machine cells and the layout of machine-cells within the workshop. In this paper, an algorithm for solving layout design has been proposed that arranges the machines within machine cells, and cells in the shop-floor in such a way that minimizes the total material handling cost. To validate the developed algorithm, the results obtained by the algorithm are compared to the results of an exhaustive search. Comparison of results shows the validity of the proposed algorithm.
\end{abstract}

Keyword: Group technology; Cellular manufacturing; Facilities planning; Simulated annealing; Exact method 